\title{
Left Ventricular Diastolic Function in Essential Hypertensive Patients. Influence of Age and Left Ventricular Geometry
}

\author{
Eduardo Cantoni Rosa, Valdir Ambrósio Moysés, Ivan Rivera, Ricardo da Cintra Sesso, \\ Nárcia Kohlmann, Maria Tereza Zanella, Artur Beltrame Ribeiro, Osvaldo Kohlmann Jr.
}

São Paulo, SP - Brazil

\begin{abstract}
Purpose - To evaluate diastolic dysfunction (DD) in essential hypertension and the influence of age and cardiac geometry on this parameter.
\end{abstract}

Methods - Four hundred sixty essential hypertensive patients (HT) underwent Doppler echocardiography to obtain $E / A$ wave ratio $(E / A)$, atrial deceleration time (ADT), and isovolumetric relaxation time (IRT). All patients were grouped according to cardiac geometric patterns (NGnormal geometry; $\mathrm{CR}$ - concentric remodeling; $\mathrm{CH}$ - concentric hypertrophy; $E H$ - eccentric hypertrophy) and to age (<40; $40-60 ;>60$ years). One hundred six normotensives (NT) persons were also evaluated.

Results - A worsening of diastolic function in the HT compared with the NT, including HT with NG (E/A: NT $1.38 \pm 0.03$ vs $H T-1.27 \pm 0.02, p<0.01)$, was observed. A higher prevalence of DD occurred parallel to age and cardiac geometry also in the prehypertrophic groups (CR). Multiple regression analysis identified age as the most important predictor of $D D\left(r^{2}=0.30, p<0.01\right)$.

Conclusion - DD was prevalent in this hypertensive population, being highly affected by age and less by heart structural parameters. DD is observed in incipient stages of hypertensive heart disease, and thus its early detection may help in the risk stratification of hypertensive patients.

Keywords: essential hypertension, diastolic function, age, cardiac geometry

Division of Nephrology, Kidney and Hypertension Hospital, Universidade Federal de São Paulo

Mailing address: Eduardo Cantoni Rosa - Rua Borges Lagoa, 960 - 04038-002 São Paulo, SP - Brazil - E-mail: kohlmann@nefro.epm.br
With the advance in noninvasive diagnostic methods, particularly through the use of Doppler echocardiography, more emphasis has been given to alterations in ventricular relaxation that occur in the course of hypertensive disease ${ }^{1-3}$.

Recent studies have shown a significant prevalence of diastolic dysfunction in selected hypertensive populations ${ }^{4-8}$, including patients who are clinically symptomatic and with normal systolic function ${ }^{9,10}$, thus rendering its recognition important for the assessment of hypertensive persons.

This fact is reinforced by the potential risk involved in the pathophysiological mechanisms of diastolic dysfunction $^{11-19}$, by the potential association with ischemic coronary disease and by the higher morbidity and lethality attributed to this condition ${ }^{20}$.

The mechanisms controlling diastolic function are complex and influenced by many variables, particularly age and the occurrence of ventricular hypertrophy ${ }^{6,8,21-25}$. However, recent studies have shown the occurrence of diastolic dysfunction in incipient phases of hypertensive heart disease ${ }^{5-7,26}$ where manifest cardiac hypertrophy is not yet present.

This fact is extremely important because early recognition of diastolic function may help in the evaluation and management of the hypertensive patient.

Few studies, however, especially in Brazil, have globally evaluated anatomical-functional cardiac correlations regarding diastolic function.

This study aims to evaluate the prevalence of diastolic function alterations using Doppler echocardiography in a reference population of essential hypertensives and the variables involved in these alterations, including age and ventricular geometry.

\section{Methods}

The study evaluated 460 patients, 129 men and 331 wo- 
men, with a diagnosis of essential hypertension. Patients with secondary hypertension, diabetes mellitus, coronary insufficiency, congestive heart failure, and renal failure were excluded from the study.

All patients were evaluated with bidimensional Doppler echocardiography, excluding those with valve lesions or low quality examinations.

In addition, 106 normotensives, 51 men and 55 women, whose blood pressure measurements on 3 consecutive occasions in a 1-week interval were lower than 140/90 $\mathrm{mmHg}$, were evaluated.

On the day echocardiography was performed, demographic parameters and pressure measurements were taken with the patient in the sitting position and after a 5 -minute rest. Among the hypertensive patients, $84.4 \%$ of the men and $86.3 \%$ of the women were receiving the usual antihypertensive treatment.

For the echocardiographic evaluation, Escote Biomédica, model SIM5000 equipment, with a mechanical $2.5 \mathrm{MHz}$ transducer, allowing bidimensional $\mathrm{M}$ mode evaluation with pulse and continuous Doppler, was used.

Measurements of left ventricular mass (LV mass) were calculated with the modified Devereux formula ${ }^{27}: 0.8[1.04$ (DIVS+DLVPW) ${ }^{3}-$ DLVD $\left.^{3}\right]+0.3$, where DIVS, DLVPW, and DLVD correspond to measurements of diastolic left interventricular septum, left ventricular posterior wall, and left ventricular diameter. For calculation of the ventricular mass index (LVMI), correction by body surface area was used. Measurements of relative thickness of the septum (RST) and wall (RWT) were obtained by 2DIVS/DLVD and 2DLVPW/DLVD, respectively ${ }^{17}$.

For the definition of hypertrophy, the usually adopted criteria for men and women were used ${ }^{28}$ : LVMI - $134 \mathrm{~g} / \mathrm{m}^{2}$ and $110 \mathrm{~g} / \mathrm{m}^{2}$. According to these criteria, the patients were classified into 4 cardiac geometry groups: normal geometry - normal LVMI and RST and RWT $<0.45$; concentric remodeling - normal LVMI and RST and/or RWT $\geq 0.45$; concentric hypertrophy - LVMI $\geq$ limits and RWT $\geq 0.45$ and eccentric hypertrophy - LVMI $\geq$ limits and RWT $<0.45$.

Diastolic function was evaluated with the following parameters: 1 - early ventricular filling (E wave) and late ventricular filling (A wave) and by the E/A wave ratio, whose normality criterion, for practical purposes, was considered $\geq 1.0 ; 2$ - measurement of the isovolumetric relaxation time (normal IRT - $<110 \mathrm{msec}$ ); 3 - atrial deceleration time (normal ADT $-<240 \mathrm{msec}$ ).

The obtained data were evaluated using the Sigma Stat program. For the global evaluation of the demographic, blood pressure, structural, and functional heart parameters, the values of means \pm standard error of the respective variables were considered.

Comparison between means of normotensive and hypertensive groups and between groups with different remodeling patterns was performed using covariance analysis after adjustment for age, sex, and body mass index (BMI) because of the demographic differences between the evaluated groups.
Spearman's correlation test was used for analysis of simple correlations.

Also, the participation of cardiac morphometric (LV MI, septum, and posterior wall) and demographic parameters as diastolic function determinants were evaluated using multiple regression analysis.

Values of $\mathrm{p}<0.05$ were considered significant.

\section{Results}

The values of means of demographic, blood pressure, and ventricular structure parameters in normotensive and hypertensive patients and hypertensive subgroups are shown in Table I.

Comparative analysis of diastolic function parameters (E/A, ADT, IRT) in hypertensives and normotensives may be seen in Figure 1, where significantly lower E/A ratios and higher IRT values can be observed in the hypertensives.

Figure 2 shows the comparison of diastolic function parameters between the hypertensive population with normal geometry and the normotensive group. It can be seen that even in the initial phases, when still no morphometric alterations are observed, significant changes already exist in the $\mathrm{E} / \mathrm{A}$ ratio.

Table II shows the mean values of diastolic parameters in hypertensive and normotensive subgroups stratified according to age and cardiac geometry. Figure 3 separately evaluates the prevalence of patients who presented an E/A ratio $<1$ in each subgroup studied.

In the first place, it can be observed that the 3 parameters were influenced by age, independently of the ventricular geometry pattern. A progressive worsening of diastolic

\begin{tabular}{|c|c|c|c|}
\hline & Normotensives & Hypertensives & $\mathrm{p}$ \\
\hline \multicolumn{4}{|c|}{106460} \\
\hline Age (years) & $41.8 \pm 1.8$ & $49.7 \pm 0.6$ & $<0.01$ \\
\hline \multicolumn{4}{|l|}{ Sex } \\
\hline male & $55(51.9 \%)$ & $129(28.1 \%)$ & $<0.01$ \\
\hline female & $51(48.1 \%)$ & $331(71.9 \%)$ & $<0.01$ \\
\hline BMI $\left(\mathrm{kg} / \mathrm{m}^{2}\right)$ & $25.3 \pm 0.5$ & $27 \pm 0.2$ & $<0.01$ \\
\hline \multicolumn{4}{|l|}{ Race } \\
\hline white & $57(54 \%)$ & $244(53.1 \%)$ & NS \\
\hline nonwhite & $49(46 \%)$ & $216(46.9 \%)$ & \\
\hline $\mathrm{SBP}(\mathrm{mm} \mathrm{Hg})$ & $116.9 \pm 1.5$ & $148.1 \pm 1$ & $<0.001$ \\
\hline $\mathrm{DBP}(\mathrm{mm} \mathrm{Hg})$ & $77.6 \pm 0.9$ & $94.9 \pm 0.6$ & $<0.001$ \\
\hline $\mathrm{HR}$ (bpm) & $73 \pm 0.8$ & $76.2 \pm 0.4$ & $<0.01$ \\
\hline DIVS (mm) & $9 \pm 0.2$ & $10.7 \pm 0.1$ & $<0.001$ \\
\hline DLVPW (mm) & $8.7 \pm 0.2$ & $10.3 \pm 0.1$ & $<0.001$ \\
\hline $\operatorname{DLVD}(\mathrm{mm})$ & $47.1 \pm 0.5$ & $46.6 \pm 0.3$ & NS \\
\hline $\mathrm{LA}(\mathrm{mm})$ & $33.5 \pm 0.5$ & $35.1 \pm 0.2$ & $<0.01$ \\
\hline $\operatorname{LVM}(\mathrm{g})$ & $142 \pm 5.5$ & $176.1 \pm 2.9$ & $<0.001$ \\
\hline $\operatorname{LVMI}\left(\mathrm{g} / \mathrm{m}^{2}\right)$ & $80.3 \pm 3$ & $103.2 \pm 2.5$ & $<0.001$ \\
\hline \multicolumn{4}{|c|}{$\begin{array}{l}\text { NS - not-significant; BMI- body mass index; SBP- systolic blood } \\
\text { pressure; DBP- diastolic blood pressure; HR - heart rate; DIVS- diastolic } \\
\text { interventricular septum; DLVPW- diastolic left ventricle posterior wall; } \\
\text { DLVD- diastolic left ventricle diameter; LA- left atrium; LVMI- left } \\
\text { ventricular mass index. }\end{array}$} \\
\hline
\end{tabular}




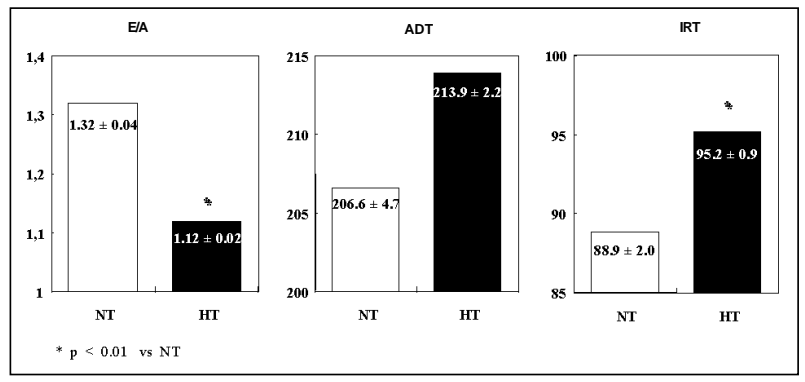

Fig. 1 - Diastolic function parameters in normotensive and essential hypertensives. ${ }^{*} \mathrm{p}<0.01$ vs NT; NT - normotensive; HT - essential hypertensive; E/A - E/A wave ratio; ADT - atrium deceleration time $(\mathrm{msec})$ IRT - isovolumetric relaxation time (msec).

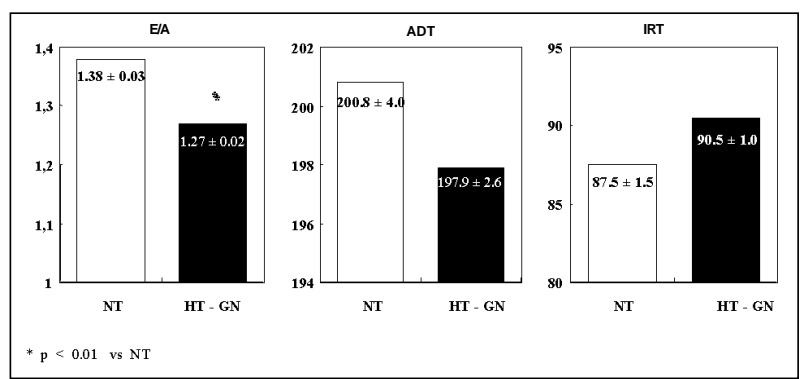

Fig. 2 - Diastolic function parameters on echocardiography in normotensive and essential hypertensives with normal geometry ${ }^{*} p<0.01$ vs NT; NT-normotensive; HT-NG-hypertensive with normal geometry; E/A - E/A wave ratio; ADT-atrium deceleration time ( $\mathrm{msec})$; IRT - isovolumetric relaxation time ( $\mathrm{msec}$ ).

function was noted with age, including in the normotensive group, where alteration in the E/A ratio was verified in 57\% of the individuals over 60 years of age (Figure 3 ).

At the same time, an effect of structural alterations is observed for all age ranges, particularly on evaluation of the $\mathrm{E} / \mathrm{A}$ ratio, where a progressive reduction in the mean values is seen already in the group with normal geometry. This fact can especially be observed in the younger age ranges $(<40$; 40-60 years).

Figure 4 shows a correlation analysis between the E/A variable and age and the heart structural parameters (LVMI, septum, and posterior wall). As expected, a close and signi-

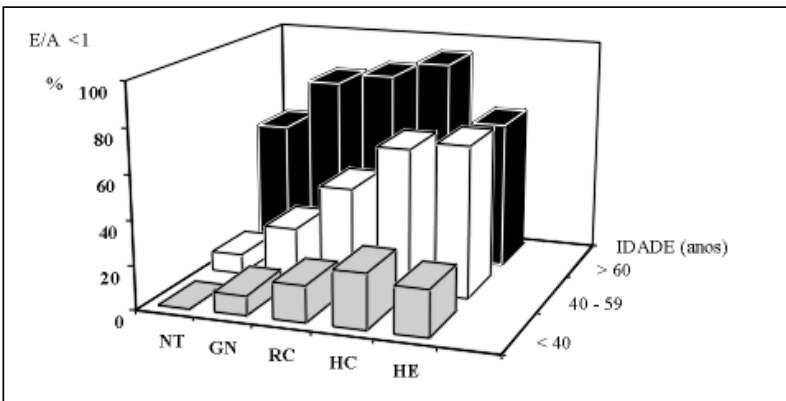

Fig. 3 - Prevalence of diastolic function in normotensive and essential hypertensive according to age and cardiac geometry. NT - normotensive; hypertensive with: NG normal geometry; $\mathrm{CR}$ - concentric remodeling; $\mathrm{CH}$ - concentric hypertrophy; $\mathrm{EH}$ excentric hypertrophy.

ficant correlation with age, and significant but lower correlations with structural parameters, especially with the septum and posterior wall were obtained.

The individual participation of morphometric cardiac (LVMI, DIVS, DLVPW), demographic (age, gender, race, BMI and time of hypertension), pressure (SBP, DBP, measured in the office), and heart rate parameters, as diastolic function determinants, using E/A ratio as a parameter, were evaluated with multiple regression analysis.

Table III shows the obtained results, only regarding variables with some predictive value, the septum and LVMI being evaluated separately. As expected, age was the most important predictive factor for alterations in the $\mathrm{E} / \mathrm{A}$ ratio $\left(\mathrm{r}^{2}=0.3 ; \mathrm{p}<0.001\right)$ with less participation by septum alterations $\left(\mathrm{r}^{2}=0.04 ; \mathrm{p}<0.0001\right), \operatorname{LVMI}\left(\mathrm{r}^{2}=0.03 ; \mathrm{p}<0.0001\right)$ and LVPW $\left(r^{2}=0.03 ; p<0.0001\right.$ - result not shown $)$.

\section{Discussion}

Evaluation of alterations in diastolic function in the hypertensive population showed that alterations are prevalent and changed in regard to normotensive patients and, as found in other studies, were influenced mainly by age $5,5,21,22,29$.

Normotensive elderly patients ( $>60$ years) reached a

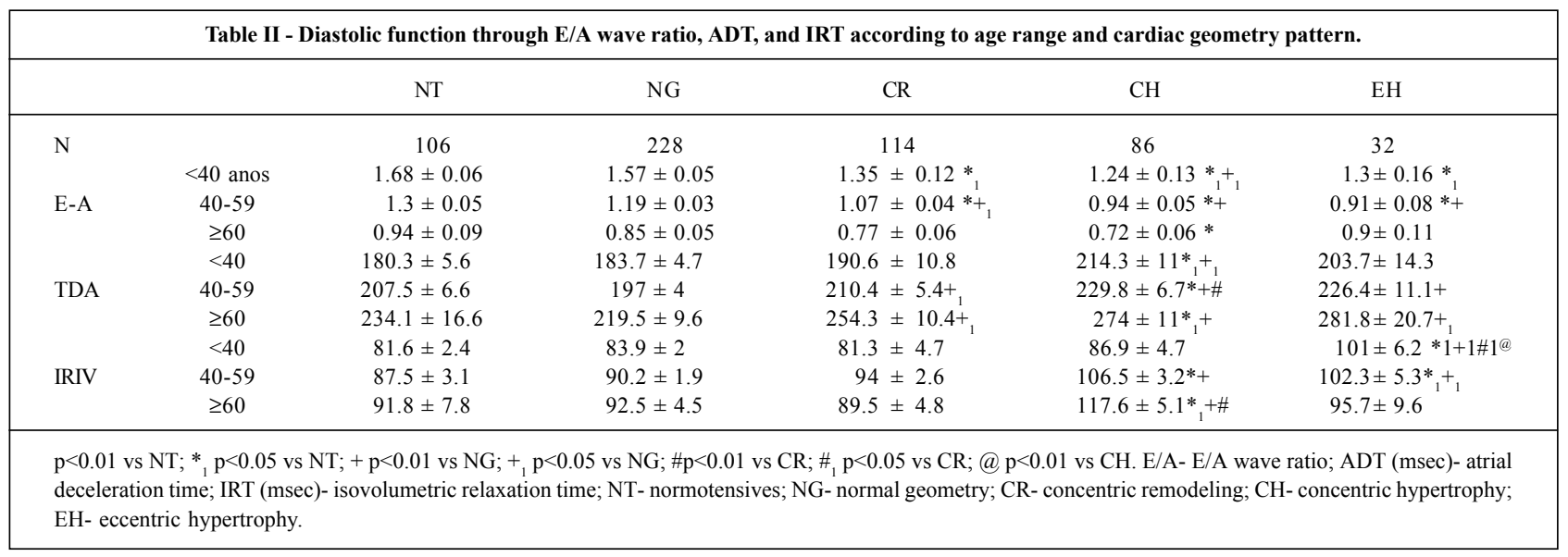




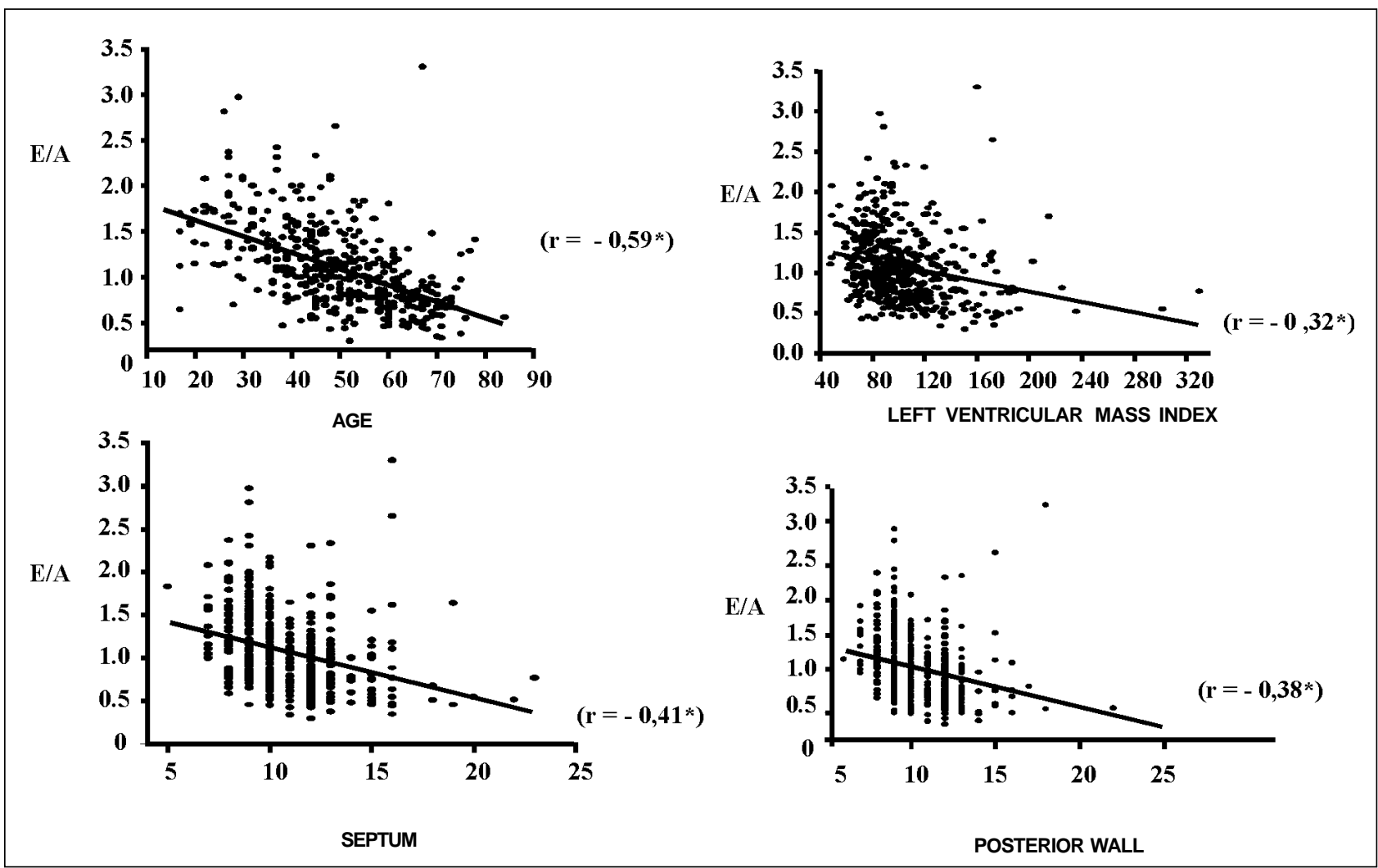

Fig. 4 - Correlation between age and heart-structural parameters and E/A ratio.

\begin{tabular}{|c|c|c|c|c|c|c|c|}
\hline \multicolumn{8}{|c|}{$\begin{array}{l}\text { Table III - Multiple regression analysis in essential hypertensives } \\
\text { according to: dependent variable - E/A ratio; independent variables - } \\
\text { age, sex, time of hypertension, systolic arterial blood pressure (SBP), } \\
\text { diastolic arterial blood pressure (DBP), heart rate, left ventricle mass } \\
\text { index (LVMI), septum. }\end{array}$} \\
\hline \multicolumn{6}{|c|}{$\mathrm{E} / \mathrm{A}$} & \multicolumn{2}{|c|}{$\mathrm{E} / \mathrm{A}$} \\
\hline Variable & Coef. & $\mathrm{R}^{2}$ & $\mathrm{P}$ & Variable & Coef. & $\mathrm{R}^{2}$ & $\mathrm{P}$ \\
\hline & 2.36 & & & & 2.34 & & \\
\hline Age & -0.017 & 0.30 & $<0.0001$ & Idade & -0.017 & 0.30 & $<0.0001$ \\
\hline Septum & -0.04 & 0.04 & $<0.0001$ & IMVE & -0.002 & 0.02 & $<0.0001$ \\
\hline Total & & 0.34 & $<0.0001$ & Total & & 0.32 & $<0.001$ \\
\hline
\end{tabular}

prevalence of $57 \%$ in alterations in the $\mathrm{E} / \mathrm{A}$ wave ratio $(<1)$, and when added to hypertension, in the groups with more important structural alterations $(\mathrm{CH})$, even a $93 \%$ inversion of the $\mathrm{E} / \mathrm{A}$ ratio could be observed.

On evaluating patients according to age range and cardiac geometry, we observed that in the elderly group, over $80 \%$ of the patients had inversion of the $\mathrm{E} / \mathrm{A}$ ratio, indicating a more permanent diastolic dysfunction, in part independent of alterations in cardiac geometry, in contrast to that in the lower age ranges.

On evaluating diastolic function measurements in hypertensives with normal ventricular mass index, significant incipient structural alterations as compared with the normotensive group were observed. Previous studies have alrea- dy emphasized the presence of diastolic dysfunction, even in the absence of hypertrophy $4,6,7,26$.

The study by Ren et al ${ }^{8}$ in 1994, in particular, evaluated measurements of diastolic function on Doppler echocardiography according to cardiac geometry and evidenced the presence of diastolic dysfunction in the prehypertrophy phases (cardiac remodeling). However, no patients with normal geometry were evaluated in this study.

The results of this study allowed us to recognize in the population evaluated by Doppler echocardiography, the early presence of diastolic dysfunction, even in the absence of structural heart disease (normal geometry) and also in the early phases of structural alteration (concentric remodeling).

As has already been emphasized, in this study, the impact of heart structural alterations on diastolic function, in contrast to findings in other studies ${ }^{23,30}$, was not very important as compared to that of age. However, the participation of these different mechanisms still remains controversial, because the data obtained at that time ${ }^{4,5,8,23,30}$, as in this study, are not uniform, there being the need for standardization of methods to detect the actual participation of structural mechanisms, both in the initial and the later phases of heart disease evolution.

When we previously emphasized the potential pathophysiological mechanisms involved in diastolic dysfunction in hypertension, its importance caught our attention. Its presence, with or without the presence of structural alterations, may certainly help in the stratification of cardiovascular risk 
in hypertensive patients, in view of the fact that in addition to the participation of structural mechanisms and age, ischemic alterations secondary to vascular hypertensive disease itself and/or atherosclerotic mechanism (coronary plaques) may be present ${ }^{13,31}$.

In this study, coronary disease was an exclusion factor for the analysis of patients, and thus we think that the initial alterations present in patients with normal geometry were subsequent to the hypertensive disease itself.

In any case, diastolic dysfunction in general hypertensive populations may imply a higher prevalence of coronary disease, as has already been emphasized by some authors ${ }^{18}$, and that may indicate a worse prognosis and demands a more detailed evaluation of the hypertensive patient.

In addition, the finding of diastolic dysfunction and left ventricular hypertrophy may imply a higher mortality ${ }^{9}$, and the presence of associated complications, such as acute pulmonary edema, may lead to more frequent hospitalizations and therefore to a higher morbidity in these patients ${ }^{20}$.

According to some studies ${ }^{9,32}$, a significant part of heart failure symptoms in the hypertensives (fatigue, exertional dyspnea) is related mainly to mechanisms of diastolic and not systolic dysfunction.

The worsening of diastolic function in groups with more severe concentric hypertrophy, particularly in the elderly, should also be noted. The latter, besides a greater preference for diastolic dysfunction ${ }^{25}$, have also more symptoms rela- ted to this entity. Therefore we have to emphasize the role of diastolic dysfunction in the mechanism of response and adaptation of cardiopulmonary reflexes to exercise maneuvers, orthostatism (tilt test), etc. ${ }^{33}$. Regarding these maneuvers, the vasoconstrictor response mechanisms, which usually are preserved in borderline hypertensives, are more impaired because of imbalance of Starling forces due to less ventricular filling. Thus, symptoms of orthostatic hypotension and exercise intolerance in individuals with sustained hypertension, especially the elderly, may be explained, leading even to anginal states, depending on the degree of coronary perfusion.

In view of the shown morbidity and the prognostic value, the presence of diastolic dysfunction may, thus, imply a treatment more directed to the hypertensive patient, avoiding unnecessary treatments, such as digitalis, diuretics, and vasodilators that may cause hypotension and symptoms of low output, and also trying to use drugs that potentially may improve the degree of diastolic dysfunction ${ }^{34}$.

In conclusion, diastolic dysfunction was prevalent in the study population of hypertensives, being greatly influenced by age and less so by heart structural alterations.

Diastolic function occurred in incipient stages of hypertensive heart disease, indicting that its early detection may lead to an additional stratification of the remodeling alterations and also guide the choice of antihypertensive drugs, avoiding those that impair the ventricular filling mechanisms.

\section{References}

1. Rokey R, Kuol C, Zoghbi WA, Limagher MC, Quinones MA. Determination of parameters of left ventricular diastolic filling with pulsed Doppler echocardiography: comparison with cineangiography. Circulation 1985; 71: 543-50.

2. Pearson AE, Labovitz AJ, Rosek D, William GA, Kennedy HL. Assessment of diastolic function in hypertrophied hearts: comparison of Doppler echocardiography and M-mode echocardiography. Am Heart J 1987; 113: 1417-25.

3. Gardin JM, Drayer JIM, Weber M, et al. Doppler echocardiographic assessment of left ventricular systolic and diastolic function in mild hypertension. Hypertension 1987; 9(suppl 2): S90-S6.

4. Inouye I, Massie B, Loge D, et al. Abnormal left ventricular filling: an early finding in mild to moderate systemic hypertension. Am J Cardiol 1984; 53: 120-6.

5. Smith VE, Schulman P, Karimeddini MK, White WB, Meeran MK, Katz AM. Rapid ventricular filling in left ventricular hypertrophy: II Pathologic hypertrophy. J Am Coll Cardiol 1985; 5: 869-74.

6. Shapiro LM, McKenna WJ. Left ventricular hypertrophy: relation of structure to diastolic function in hypertension. Br Heart J 1984; 51: 637-42.

7. Snider AR, Gidding SS, Rochini AP, et al. Doppler evaluation of left ventricular diastolic filling in children with systemic hypertension. Am J Cardiol 1985; 56: 921-6.

8. Ren JF, Pancholy SB, Iskandrian AS, Lighty GW, Mallavarapu C, Segal BL. Doppler echocardiographic evaluation of the spectrum of left ventricular diastolic dysfunction in essential hypertension. Am Heart J 1994; 127: 906-12.

9. Cohn JN, Johnson G. Heart failure with normal ejection fraction: the V-Heft Study. Circulation, 1990; 81(suppl 111): 48-53.

10. Iriarte M, Munga $N$, Sagastogoitia D. Congestive heart failure from left ventricular diastolic dysfunction in systemic hypertension. Am J Cardiol 1993; 71: 308-12.

11. Shepherd RF, Zachariah PK, Shub C. Hypertension and left ventricular diastolic function. Mayo Clin Proc 1989; 64: 1521-32.

12. Perreault CL, Williams CP, Morgan JP. Cytoplasmatic calcium modulation and systolic versus diastolic dysfunction in myocardial hypertrophy and failure. Circulation, 1993; 87(suppl V11): 31-7.

13. Kannel WB, Dawber TR, Kogan A, Revotskie N, Stokes J. Factors of risk in the development of coronary heart disease. Six years of follow-up experience. Am Intern Med 1961; 55: 33-50.

14. Marcus ML, Koyanagi S, Harrison DG, Doty DB, Hiratzka LF, Eastham CL. Abnormalities in the coronary circulation that occur as a consequence of cardiac hypertrophy. Am J Med 1983; 75(suppl 3): 62-6.

15. Houghton J, Frank MJ, Carr AA, van Dohlen TW, Prisant LM. Relations among impaired coronary flow reserve, left ventricular hypertrophy and thallium perfusion defects in hypertensives patients without obstrutive coronary artery disease. J Am Coll Cardiol 1990; 15: 43-51.

16. Gardin JM, Rohan MK, Davidson DM, et al. Doppler transmittal flow velocity parameters: relationship between age, body surface area, blood pressure and gender in normal subjects. Am J Noninvas Cardiol 1987; 1: 3-10.

17. Jalil JE, Doering CW, Janicki JS, Pick R, Shroff SG, Weber RT. Fibrillar collagen and myocardial stiffness in the intact hypertrophied rat left ventricle. Circ Res 1989; 64: 1041-50.

18. Frohlich ED, Epstein C, Chobarrian AV, et al. The heart in hypertension. N Engl J Med 1992; 327: 998-1013.

19. Lorell BH, Grossman W. Cardiac hypertrophy: the consequences for diastole. J Am Coll Cardiol 1987; 9: 1189-93.

20. Brogan WC, Hillis D, Flores ED. The natural history of isolated left ventricular diastolic function. Am J Med 1992; 92: 627-30.

21. White WB, Schulman P, Dey HM. Effects of age and 24-hour ambulatory blood pressure on rapid left ventricular filling. Am J Cardiol 1989; 63: 1343-7.

22. Galderisi M, Petrocelli A, Alfieri A. Impact of ambulatory blood pressure on left ventricular diastolic function in uncomplicated arterial systemic hypertension. Am J Cardiol 1996; 77: 597-601.

23. Fouad FM, Slominski JM, Tarazi RC. Left ventricular diastolic function in hypertension: relation to left ventricular mass and systolic function. J Am Coll Cardiol; 3: $1500-6$.

24. Bonaduce D, Breglio R, Conforti G, et al. Myocardial hypertrophy and left ventricular diastolic function in hypertensive patients: an echo Doppler evaluation. Eur Heart J 1989; 10: 611-21. 
25. Zabalgoitia M, Rahman NU, Haley W, et al. Comparison in systemic hypertension of left ventricular mass and geometry with systolic and diastolic function in patients $<65$ to $>65$ years of age. Am J Cardiol 1998; $82 ; 604-8$.

26. Zabalgoitia M, Rahman NU, Haley W, et al. Disparity between diastolic mitral flow characteristics and left ventricular mass in essential hypertension. Am J Cardiol 1997; 79; 1255-8.

27. Devereux RB,AlonsoDR, LutasEM.Echocardiographic assessmentofleft ventricular hypertrophy: comparison to necropsy findings. Am J Cardiol 1986; 57: 450-8.

28. Devereux RB, Lutas EM, Casale PN. Standardization of M- mode echocardiographic left ventricular anatomic measurements. J Am Coll Cardiol 1984; 4: 1222-30.

29. Klein A L, Burstow DJ, Tajik J. Effects of age on left ventricular dimensions and filling dynamics in 117 normal persons. Mayo Clin Proc 1994; 69: 212-24.
30. Granger CB, Karimeddini MK, Smith VE, Shapiro HR, Katz AM, Riba AL. Rapid ventricular filling in left ventricular hypertrophy. I - Physiologic hypertrophy. J Am Coll Cardiol 1985; 5: 862-8.

31. Folkow B. Cardiovascular structural adaptation: its role in the initiation and maintenance of primary hypertension. Clin Sci Mol Med 1978; 55: 3-22.

32. Lee DC, Johnson RA, Bingham JB, et al. Heart failure in outpatients: a randomized trial of digoxin versus placebo. N Engl J Med 1994; 306: 699-705.

33. Pearson AC, Gudipati CV, Labovitz AJ. Systolic and diastolic flow abnormalities in elderly patients with hypertensive hypertrophic cardiomyopathy. J Am Coll Cardiol 1988; 12: 989-95.

34. Mayet J, Shahi M, Pouter N. Left ventricular diastolic function in hypertension: a four year follow-up study. Int J Cardiol 1995; 50: 181-8.

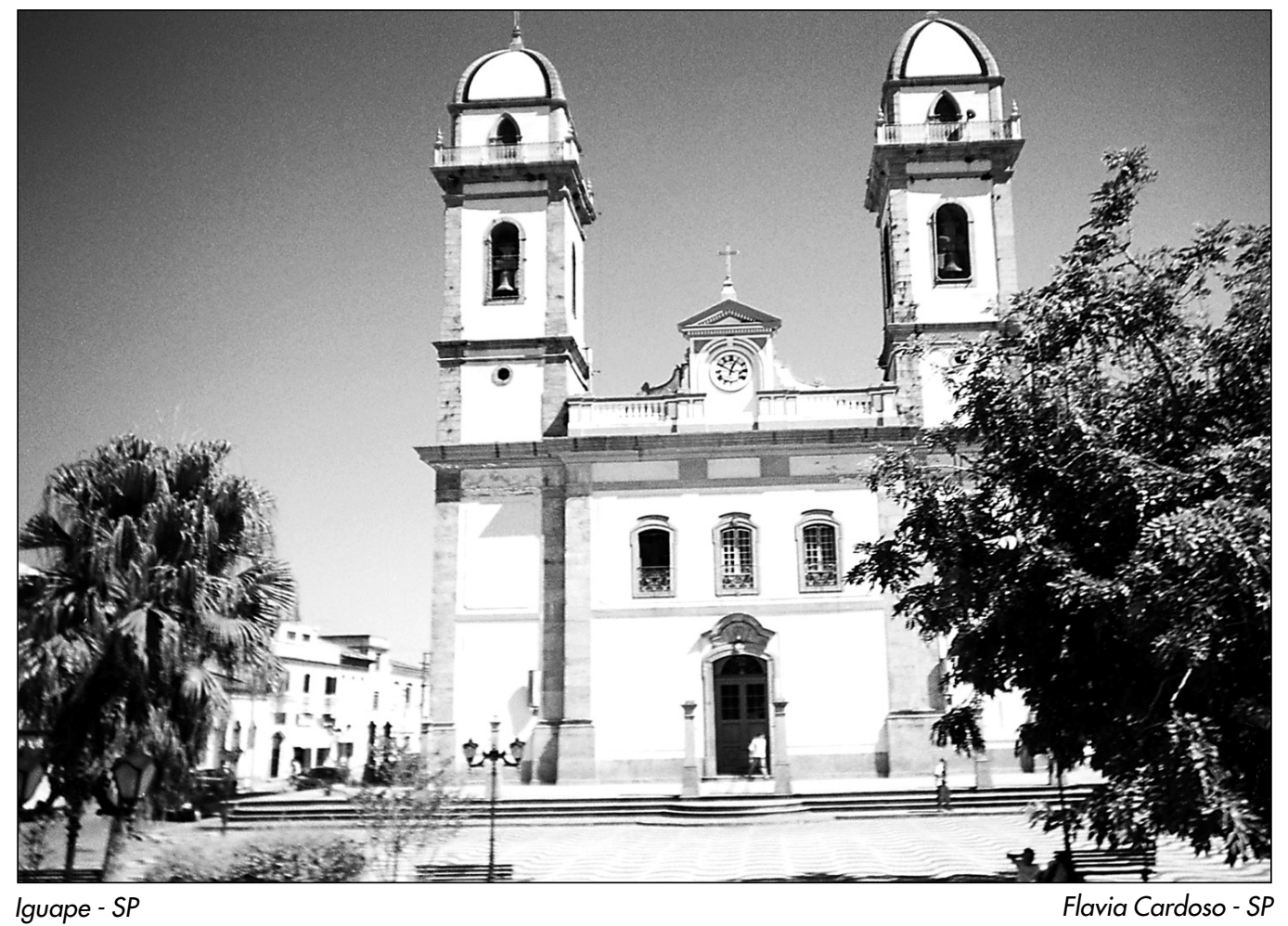

Editor da Seção de Fotografias Artísticas: Cícero Piva de Albuquerque

Correspondência: InCor - Av. Dr. Enéas C. Aguiar, 44 - 05403-000 - São Paulo, SP - E-mail: delcicero@incor. usp.br 